\title{
Selim kemik tümörleri: Sınıflama, klinik ve radyolojik özellikler, biyopsi
}

\section{Benign bone tumors: classification, clinical and radiological findings, biopsy}

\author{
Bülent Erol, Nadir Aydemir
}

Marmara Üniversitesi, Pendik Eğitim Araştırma Hastanesi, İstanbul

\begin{abstract}
Primer kemik tümörleri nadirdir ve genellikle selim tümörlerle karşılaşılır. Selim ve habis kemik tümörleri çocuklarda ve genç erişkinlerde daha sık görülür. Özelleşmiş merkezlere zamanında sevk edilebilmeleri için kas-iskelet sistemi tümörlerinin klinik ve radyolojik özelliklerinin bilinmesi gerekir. Dikkatli bir hikâye ve fizik muayeneyi takiben kemik lezyonunun görüntüleme çalışmaları değerlendirilmelidir. İskelet lezyonları hakkında en detaylı bilgiyi konvansiyonel radyografiler verir ve radyografik değerlendirme ile selim ve habis kemik tümörlerini birbirlerinden ayırt etmek sıklıkla mümkündür. Biyopsi tanının en son aşamasıdır ve definitif ameliyatı gerçekleştirecek cerrah tarafından yapılmalıdır. Habis bir kemik tümörünün erken tanısı sadece yaşam ile ölüm arasındaki farkı belirlemekle kalmaz, aynı zamanda bir ekstremitenin kurtarılması veya ampüte edilmesini de belirler.
\end{abstract}

Anahtar sözcülkler: selim; kemik tümörleri; radyografi; biyopsi
Primary bone tumors are uncommon, and when they occur, are usually benign. Both benign and malignant bone tumors are seen more commonly in children and young adults. Physicians should be aware of the clinical and radiological manifestations of musculoskeletal tumors in order to provide timely specialist referrals. Imaging studies of the bony lesion should be evaluated, carefully following the history and physical examination. Plain radiographs give the most detailed information about skeletal lesions and it is frequently possible to differentiate a benign bone tumor from a bone sarcoma by radiographic evaluation. A biopsy is the final step in diagnosis and should be done by the surgeon who will perform the definitive procedure. Early detection of a malignant bone tumor may make the difference not only between life and death but also between saving or amputating a limb.

Key words: benign; bone neoplasms; radiography; biopsy
K emik tümörleri primer (selim/habis) veya metastatik olabilir. Metastatik tümörler primer tümörlere kıyasla, primer selim kemik tümörleri ise habis olanlara göre çok daha fazla görülür. Selim ve habis kemik tümörlerinin büyük kısmı en sık çocukluk ve ergenlik döneminde ortaya çıkar ve bu dönemdeki bulgular sıklıkla başka nedenlere bağlanır. Bu tümörlerde ilk yaklaşımın gecikmesi veya uygun şekilde yapılamaması nadir karşılaşılan durumlar değildir. Kemik tümörlerinin klinik ve radyografik özellikleri hakkında bilgi sahibi olunması bu olguların özelleşmiş merkezlere daha erken sevk edilmelerini, dolayısıyla erken tanı ve tedavilerini sağlar. özgün klinik (anamnez, fizik muayene, laboratuvar tetkikleri) ve radyolojik özelliklerin tanı algoritmasına uygun şekilde değerlendirilmesi ve histopatolojik inceleme (biyopsi) tanıya ulaşılmasını sağlar. Selim kemik tümörlerinin tanı, evreleme ve tedavi aşamalarında çoğu zaman ortopedik onkoloji, radyoloji ve patoloji bölümlerinin işbirliği yeterli olur. Habis tümörlerde tedaviye sıklıkla katkıda bulunan tıbbi onkoloji ve radyasyon onkolojisi bölümlerine ise nadiren ihtiyaç duyulur.

Primer kemik tümörleri köken aldıkları dokuya göre sınıflandırılır; her bir histogenetik tip kendi içinde selim ve habis lezyonlar içerir (Tablo 1). Selim tümörler lokal invazyon eğilimleri az olan, sınırlı otonom büyüme kapasitesine sahip neoplazilerdir. Sarkomlar ise agresif büyüme kapasitesine sahiptir ve uzak metastatik yayıIım potansiyeli taşırlar. Kemik lezyonlarının biyolojik davranışlarına göre sınıflanması da yararlıdır (Tablo 2). Buna göre kemik tümörleri 'selim', 'selim fakat lokal agresif' ve 'habis' neoplaziler şeklinde gruplanabilir. Selim lezyonlar grubu, latent ve aktif selim kemik tümörlerini içerir. Latent tümörler genellikle sessiz asemptomatik

- İletişim adresi: Doç. Dr. Bülent Erol, Marmara Üniversitesi, Pendik Eğitim Araştırma Hastanesi, Ortopedi ve Travmatoloji Kliniği, Pendik, Kaynarca, İstanbul Tel: 0216 - 6570606 e-posta: bulerol@hotmail.com

- Geliș tarihi: 27 Eylül $2013 \quad$ Kabul tarihi: 27 Eylül 2013 
TABLO 1. Kemik tümörlerinin histogenetik kökene göre sınıflanması

- Kemik-oluşturan (osteojenik) lezyonlar

- Kıkırdak (kondrojenik) lezyonları

- Fibrojenik, fibroosseöz ve fibrohistiyositik lezyonlar

- Yuvarlak hücreli lezyonlar

- Çeşitli/tümör benzeri lezyonlar
Osteoid osteoma, osteoblastoma, osteosarkom

Osteokondrom, enkondrom, kondroblastom, kondromiksoid fibrom, kondrosarkom

Nonossifiye fibrom, fibröz displazi, osteofibröz displazi, fibrosarkom, malign fibröz histiositom

Eozinofilik granülom, Ewing sarkomu-PNET, lenfoma, multipl miyelom Basit kemik kisti, anevrizmal kemik kisti, dev hücreli tümör

TABLO 2. Kemik tümörlerinin biyolojik davranışa göre sınıflanması

- Selim lezyonlar

- Selim ama lokal agresif lezyonlar

- Habis lezyonlar
Osteoid osteoma, osteokondrom, enkondrom, nonossifiye fibrom, fibröz displazi, eozinofilik granülom, basit kemik kisti

Osteoblastoma, kondroblastom, kondromiksoid fibrom, osteofibröz displazi, anevrizmal kemik kisti, dev hücreli tümör

Osteosarkom, kondrosarkom, fibrosarkom, malign fibröz histiositom, Ewing sarkomu-PNET, multipl miyelom-plazmositom bir seyir izler ve rastlantısal olarak saptanır. Aktif tümörler ise kemik içinde büyüyerek semptomatik seyredebilir, bazen patolojik kırık oluşturabilir. Selim fakat lokal agresif lezyonlar, hem klinik hem de radyolojik olarak daha saldırgandır ve kompartman dışı yayılım gösterebilir. Bu grupta bulunan neoplaziler çok nadir de olsa uzak metastaz potansiyeline sahiptir. Habis lezyonlar ise, hem lokal yayılım hem de uzak metastaz potansiyelleri yüksek olan tümörlerdir.

\section{KLINIK BULGULAR}

Detaylı anamnez ve fizik muayene doğru tanıya ulaşmada önemlidir. Anamnezden elde edilebilecek en önemli bilgi hastanın yaşıdır, çünkü belli tümörler belirli yaş aralıklarında daha sık görülme eğilimindedir (Tablo 3). ${ }^{[1]}$ Bazı kemik tümörlerinde cinsiyet farkı belirgin olsa da bu durum nadiren tanısal önem taşır. Aynı şekilde ırkın da belirleyiciliği sınırlıdır. ${ }^{[2]}$

Ağrı, şişlik/kitle, patolojik kırık ve rastlantısal radyografik bulgu kas-iskelet sistemi tümörlü hastaların başlıca başvuru nedenlerini oluşturur (Tablo 4). ${ }^{[1]}$ Ağrı genellikle ilk bulgudur; süresi, yerleşimi, şiddeti, karakteri ve nasıl azalıp arttığı sorgulanmalıdır. Aktif veya agresif selim kemik tümörü (ör., anevrizmal kemik kisti, kondroblastom) olan hastalar genellikle hafif, yavaş ilerleyen ve aktivite ile artan bir ağrıya sahiptirler. Bu, habis kemik tümörü olan hastalardaki hızlı ilerleyen, aktivite ile ilişkisi olmayan ve gece uykudan uyandıran ağrı paterninden farklıdır. Ağrı uzun süredir mevcutsa daha ön planda selim süreçler akla gelmelidir. Ağrı, osteoid osteoma da olduğu gibi tipik bir patern izliyorsa (geceleri artan, aspirin veya nonsteroid antiinflamatuvar ilaçlar [NSAii] ile geçici olarak kaybolan) nadiren tanısal değer taşıyabilir.

Yumuşak doku tümörlerinin temel bulgusu olan ve habis kemik tümörlerine de sıklıkla eşlik eden (habis kemik tümörünün kompartman dışına yayılımı sonucu) şişlik/kitle oluşumu, selim kemik tümörlerinde daha nadiren görülen bir bulgudur. Bu durumda, şişliğin/kitlenin ne kadar zamanda oluştuğu ve hangi hızda büyüdüğü öğrenilmeli, kıvamı ve mobilitesi muayene edilmelidir. Agresif neoplastik süreçler genellikle haftalar veya aylar içinde yavaşça büyüyen ağrısız kitleler ile görülebilirler. Selim kemik tümörlerine sıklıkla patolojik kırıklar eşlik eder; bunların çoğunluğu mikrokırıklardır; nadiren daha şiddetli, deplase kırıklar görülebilir. ${ }^{[3]}$ Daha öncesine ait bulgular olmaksızın gelişen patolojik kırıklarda, çoğunlukla kemiği zaman içinde zayıflatan ve sonunda da bir yorgunluk kırığına sebebiyet veren selim bir tümörden şüphelenilmesi gerekir. Selim agresif ve habis tümörler ise sıklıkla kemik kırılacak kadar zayıflamadan önce ağrı yapar. Son olarak, asemptomatik kemik tümörleri başka nedenlerle çekilen radyografilerde de rastlantısal olarak saptanabilir.

Kitlenin değerlendirilmesi (eğer varsa), ekstremitenin nörovasküler muayenesinin yapılması, komşu eklemin hareket açıklığına bakılması ve hastanın yürüme paterninin gözlenmesi, fizik muayenenin başlıca unsurlarını oluşturur. Kas-iskelet sistemi tümörü olan hastaların çoğunluğu ateş, lökositoz, yüksek eritrosit sedimentasyon hızı gibi sistemik bulgulara sahip değildir. Primer 
TABLO 3. Kemik tümörlerinin sık görüldüğü yaş aralıkları

\begin{tabular}{cll}
\hline Yaş & Selim & Habis \\
\hline $0-5$ & Eozinofilik granülom & Ewing sarkomu \\
$5-10$ & Basit kemik kisti & Osteosarkom \\
& Anevrizmal kemik kisti & Ewing sarkomu \\
& Nonossifiye fibrom & \\
& Fibröz displazi & \\
& Osteoid osteoma & \\
& Eozinofilik granülom & \\
$10-20$ & Fibröz displazi & Osteosarkom \\
& Osteoid osteoma & Ewing sarkomu \\
& Anevrizmal kemik kisti & \\
& Kondroblastom & \\
& Osteofibröz displazi & \\
Erişkin & Dev hücreli tümör & Multipl miyelom \\
& Enkondrom & Kondrosarkom \\
& & Metastatik karsinom
\end{tabular}

habis kemik tümörlü hastalar bile genellikle sağlıklı görünürler. Bunun yanı sıra, nadiren de olsa sistemik bulgular bazı selim ve habis kemik tümörlerine (ör., eozinofilik granülom, Ewing sarkomu) eşlik edebilir. ${ }^{[4]}$

\section{RADYOLOJIK ÖZELLIKLER}

Görüntüleme çalışmaları cerrahi işlemlerden (biyopsiyi de içeren) önce yapılmalıdır. Primer tümörü saptama ve tanı koyma, tümörü sınıflandırma, biyopsi yaklaşımını ve cerrahi tekniği belirleme bu çalışmaların amaçları içindedir. Selim kemik tümörlerinin tanı ve evrelemesinde başta konvansiyonel radyografiler olmak üzere, bilgisayarlı tomografi (BT), manyetik rezonans (MR) görüntüleme ve sintigrafi sıklıkla ihtiyaç duyulan tetkiklerdir.

Radyografik inceleme ayırıcı tanının yapı taşıdır. Konvansiyonel radyografiler kemik lezyonlarının değerlendirilmesinde tüm diğer görüntüleme yöntemlerine kıyasla daha fazla bilgi verir ve selim bir lezyonun bir kemik sarkomundan ayırt edilmesi temel olarak detaylı radyografik incelemeye dayanır. Hastanın, özellikle yaşını içeren klinik bilgi ve radyografik bulguları birleştirildiğinde tanıya sıklıkla ulaşılabilir. İskelet lezyonları iyi kalitede radyografilerde, lezyonun tamamı iki yönlü görüntülenerek incelenmelidir. Radyografik değişikliklerin ancak kemiğin \%30-40'ı destrükte olduğunda görülebildiği ve kemik lezyonlarının yumuşak doku uzanımlarının konvansiyonel radyografilerde saptanmasının zor olacağı unutulmamalıdır. Kemik lezyonlarını konvansiyonel radyografilerde değerlendirilirken bazı
Tablo 4. Selim kemik tümörlerinin klinik bulguları

\begin{tabular}{ll}
\hline - Ağrı & Süresi \\
& Yerleşimi \\
& Şiddeti \\
& Karakteri \\
& Nasıl artıp azaldığı \\
& Süresi \\
- Şişlik-Kitle & Büyüklüğü \\
& Kıvamı \\
& Mobilitesi \\
- Patolojik kırık & \\
- Rikrokırık $\rightarrow$ deplase kırık) & Önceye ait bulgular \\
& Kırık mekanizması \\
& Kırı̆̆ın karakteristikleri \\
& Önceye ait bulgular \\
& Radyografiler neden çekildi?
\end{tabular}

soruların sorulması ayırıcı tanıya yönelik daha sistematik bir incelemeye olanak tanır (Tablo 5$)^{[5]}$ :

- Lezyon kemiğin neresinde yerleşmiştir?

- Lezyonun kemiğe etkisi nedir?

- (Sağlam) kemiğin lezyona cevabı nasıldır?

- Periost cevabı nasıldır?

Radyografik inceleme lezyonun yerinin belirlenmesi ile başlamalıdır çünkü birçok kemik tümörünün iskeletin belirli bölgelerine afinitesi vardır (Tablo 6). Kemik lezyonları uzun kemik içinde epifizyel, metafizyel veya diafizyel yerleşimli olabilirken, medulla (santral, eksentrik) veya korteksten (intrakortikal) köken alabilir. Epifizyel bir lezyonun tanısı iskelet matüritesi öncesinde muhtemelen kondroblastom, daha büyük yaşlarda ise dev hücreli kemik tümörü şeklinde olacaktır. Aynı şekilde diafiz yerleşimli lezyonların ayırıcı tanısında bu bölgeye afinitesi olan tümörler ilk planda akla gelmelidir (Tablo 7). ${ }^{[1]}$ Erişkin hastalarda saptanan vertebra lezyonlarının çoğunluğu metastaz, miyelom veya hemanjiyomları içerir. Genç hastalarda ise vertebral korpus tutulumunda histiositoz, posterior elemanların tutulumunda ise anevrizmal kemik kisti veya osteoblastom olası tanılardır. ${ }^{[2,3]}$

Kemik lezyonu yerleştiği kemiği destrükte edebilir veya onunla yer değiştirebilir; destrüksiyon radyografilerde 'coğrafik', 'permeatif' veya 'güve-yeniği' şeklinde tanımlanır (Şekil 1). ${ }^{[6]}$ Bu özelliklerin hiçbiri belli bir tümör için patognomik olmamakla beraber sürecin selim veya habis gidişatı hakkında bilgi verebilir. 
Tablo 5. Kemik tümörlerinin radyografik özellikleri
- Yerleşim ve köken alınan yer
- Epifizyel, metafizyel, diafizyel
- Medüller (santral, eksentrik), intrakortikal
- Kemik destrüksiyonunun tipi
- Coğrafik destrüksiyon; yavaş büyüyen statik lezyonlar
- (Sağlam) kemik cevabı
- Permeatif, güve-yeniği destrüksiyon; hızlı büyüyen agresif lezyonlar
- Periost cevabı
- Sklerotik halka veya korteks ile sınırlı; statik lezyon
- Kortikal bütünlügün bozulması ve yumuşak doku uzanımı; agresif lezyon
- Farklı paternlerde olabilir (ör., spiküllü, lamellar/soğan-zarı, Codman üçgeni)

TABLO 6. Özgün kemik tümörlerinin sık yerleştiği bölgeler

\begin{tabular}{ll}
\hline Epifiz & Metafiz \\
\hline Kendroblastom & Herhangi bir tümör \\
& \\
Diafiz & Multipl \\
\hline Fibröz displazi & Multipl herediter egzositoz \\
Eozinofilik granülom & Eozinofilik granülom \\
Osteofibröz displazi & Poliostotik fibröz displazi \\
Adamantinoma & Enkondromatozis \\
Lenfoma & \\
Anterior omurga & Posterior omurga \\
\hline Eozinofilik granülom & Anevrizmal kemik kisti \\
Hemanjiom & Osteoblastom \\
Miyelom, metastaz & Osteoid osteom \\
& \\
PELvis & KOSTA \\
\hline Osteokondrom & Fibröz displazi \\
Eozinofilik granülom & Eozinofilik granülom \\
Ewing sarkomu & \\
Kondrosarkom & \\
& \\
\hline
\end{tabular}

Coğrafik kemik destrüksiyonu keskin sınırlar içinde uniform olarak yıkıma uğramış bir alanı ifade eder; nonossifiye fibrom, basit kemik kisti gibi statik veya yavaş büyüyen selim lezyonlar genellikle kemikte bu tip bir yıkım oluştururlar. Coğrafik destrüksiyonda lezyon ile sağlam kemik birbirlerinden kolaylıkla ayırt edilebilir, arada çok dar bir 'geçiş zonu' mevcuttur (Şekil 2 a, b). Kötü sınırlı, çok küçük oval radyolusen alanlar ile karakterize permeatif destrüksiyon veya multipl küçük sıklıkla kümeleşmiş litik alanlardan oluşan güve-yeniği destrüksiyon ise Ewing sarkomu, osteosarkom, lenfoma gibi hızlı büyüyerek yerleştiği kemiği infiltre eden habis tümörleri işaret eder. Permeatif
TABLO 7. Diafizyel Lezyonların Ayırıcı Tanısı

\begin{tabular}{ll}
\hline - Ewing sarkomu & 5-25 yaş \\
- Lenfoma & Erişkin \\
- Fibröz displazi & 5-30 yaş \\
- Adamantinoma & Erişkin, tibiada \\
- Eozinofilik granülom & 5-30 yaş
\end{tabular}
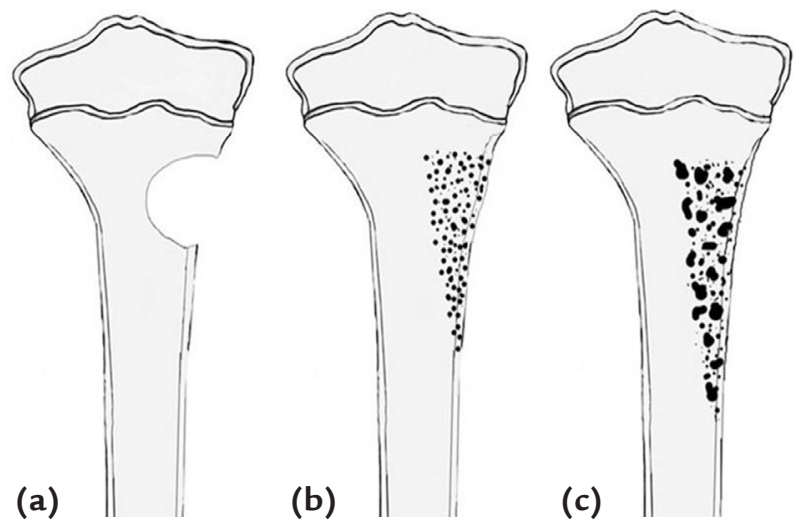

Şekil 1. a-c. Kemik tümörlerinin oluşturduğu farklı destrüksiyon tipleri: sırasıyla, coğrafik (a), permeatif (b) ve güve-yeniği (c). Selim kemik tümörleri çoğunlukla coğrafik tarzda kemik destrüksiyonu ile karakterizedir.

veya güve-yeniği tarzında destrüksiyonda lezyonla sağlam kemik arasındaki geçiş keskin değildir.

Kemiğin neoplastik sürece yanıtı komşu korteks ve periostun cevabını içerir. Selim kemik tümörleri yavaş büyüyen, statik lezyonlardır ve genellikle sklerotik kemikle çevrelenir veya korteks tarafindan sınırlanırlar. Nonossifiye fibrom/fibröz kortikal defekt gibi statik lezyonlar çoğu zaman sklerotik bir halka ile çevrelenirler (Şekil 3a). Basit kemik kistleri ve çoğu anevrizmal kemik kisti ise yerleştiği kemiği genişletip korteksi inceltmekle beraber genellikle ince bir korteks (bazen sadece periost) ile sınırlanır (Şekil 3b). Selim agresif veya 

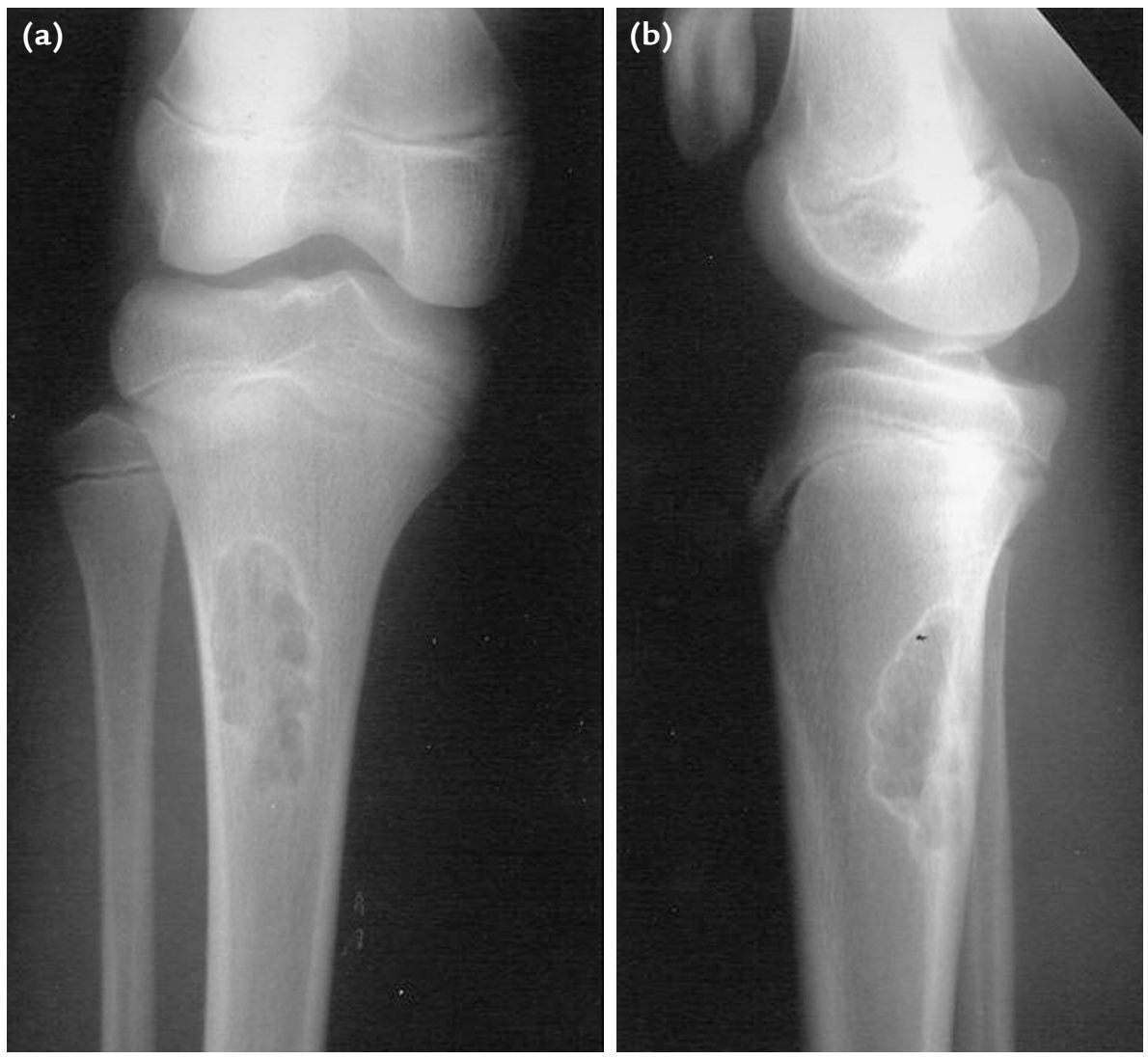

Şekil 2. a, b. Proksimal tibia yerleşimli bir nonossifiye fibromun anteroposterior (a) ve lateral (b) radyografileri. Fibröz doku kökenli bu selim tümör kemikte coğrafik destrüksiyon oluşturmuş; tümörle sağlam kemik birbirlerinden kolaylıkla ayırt edilebilmekte, arada dar bir 'geçiş zonu' mevcut.

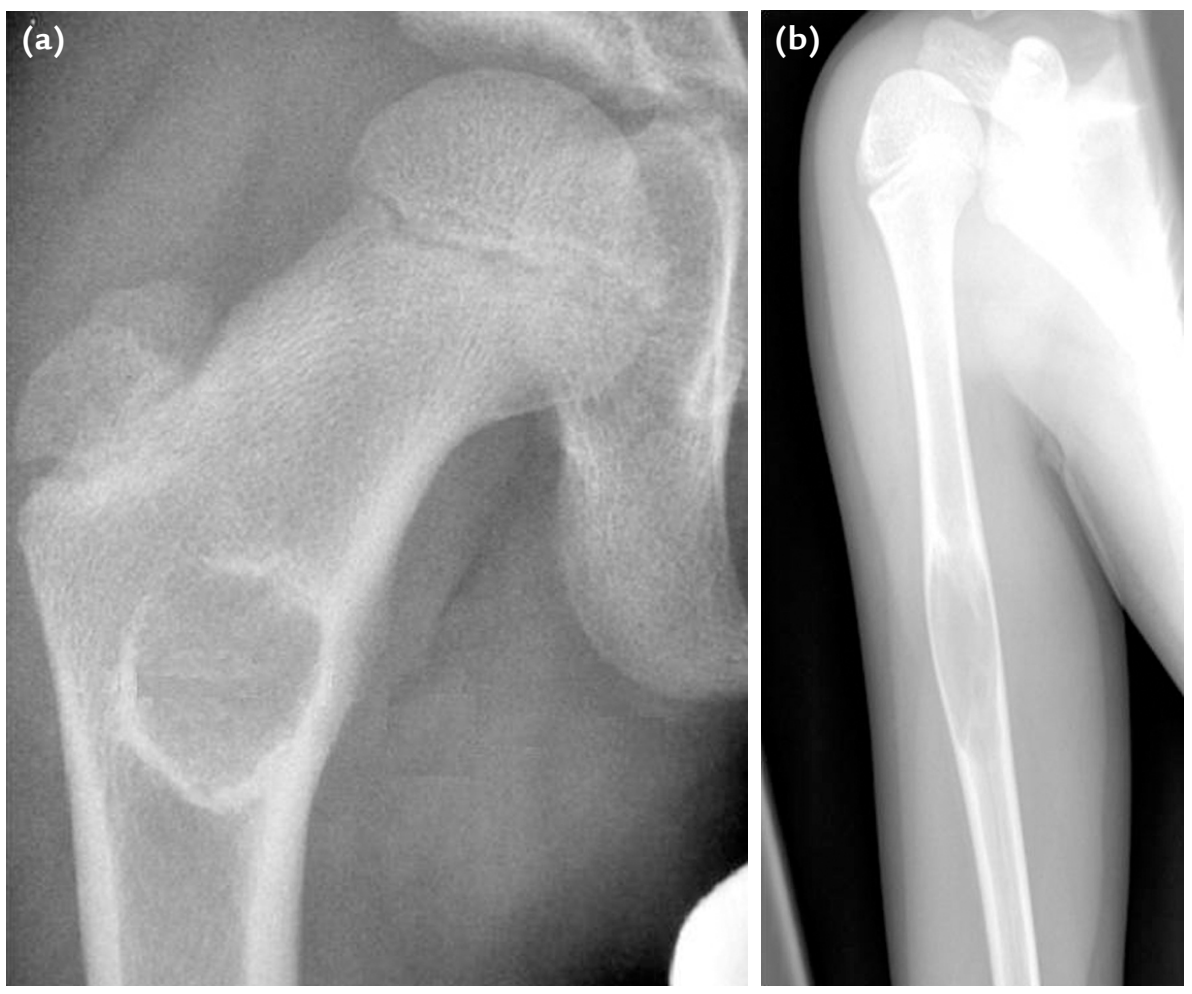

Şekil 3. a, b. Yavaş büyüyen selim kemik tümörleri genellikle sklerotik kemik tarafından çevrelenir veya korteks tarafından sınırlanırlar. Proksimal femur yerleşimli bir nonossifiye fibromun sklerotik kemikle çevrelendiği (a) ve humerus diafiz yerleşimli bir basit kemik kistinin ekspansiyon ve kortikal incelmeye neden olmakla beraber korteks tarafından sınırlandığı (b) görülmekte. 
habis neoplastik süreçler ise korteksi parçalayabilir ve bir yumuşak doku kitlesi oluşturabilirler.

Kemik destrüksiyonun tipi gibi periost reaksiyonun varlığı ve paterni de lezyonun biyolojik aktivitesi açısından bir göstergedir. Kemik çeperindeki herhangi bir genişleme veya düzensizlik periosteal aktivite şeklinde görülebilir. Kemik tümörlerine devamlı veya kesintili tipte periost reaksiyonları eşlik edebilir. ${ }^{[7]}$ Belirli bir kemik lezyonu için tek tip bir periost aktivitesi özgün olmamakla beraber, devamlı tipte periost reaksiyonu uzun-süreli (yavaş-büyüyen) selim bir süreci işaret eder (ör., eozinofilik granülom). Diğer taraftan, kesintili periost reaksiyonu ise daha sık olarak habis tümörlerde görülür; bu lezyonlarda periost reaksiyonu ışınsal (hair-on-end) veya soğan-zarı (lamellar) tarzında olabilir (Şekil $4 \mathrm{a}, \mathrm{b}$ ). Tümörün periferinde reaktif bir periosteal kılıf, Codman üçgeni, oluşabilir.

Kemik tümörlerinin radyografik ayırıcı tanısında kullanılabilecek diğer bir özellik lezyonun matriks özellikleridir. Matriks mezenkimal hücreler tarafından üretilen intersellüler materyaldir ve osteoid, kemik, kondroid, miksoid ve kollajen doku içerebilir. Matriks tipinin tayini bazı benzer görünümde lezyonların ayırt edilebilmelerini sağlar, özellikle de osteoblastik ve kondroblastik süreçleri ayırmada yardımcı olur. ${ }^{[8]}$ Tümöre bağlı oluşan kemiğin, reaktif skleroz (ör., osteoid osteoma) veya kallus formasyonu ile depolanan reparatif kemikten radyografik ayrımı güç olabilir. Fakat kemik destrüksiyonu içinde veya komşuluğunda düzensiz, tam mineralize olmamış kemik matriksin varlığı osteosarkom tanısını kuvvetle destekler (Şekil 5 a, b). Benzer şekilde medüller kavitede ve komşu yumuşak dokuda pamuğa benzer bir görünüm de büyük olasılıkla tümöre bağlı kemiği-osteosarkomu işaret eder. Diğer taraftan tümör matriks içinde kalsifikasyonlar kondroblastik neoplaziler lehinedir. Bu düzensiz şekilli punktat kalsifikasyonlar, selim ve iyi-diferansiye habis tümörlerde endokondral ossifikasyon sürecini yansıtırlar; ayırıcı tanıda enkondrom, kondroblastom ve kondrosarkom yer alır (Şekil 5c).

\section{İleri görüntüleme}

Klinik değerlendirme ve konvansiyonel radyografilerin incelenmesi sonrası birçok kemik tümörüne doğru şekilde tanı konabilir. İlave görüntüleme çalışmaları özgün tanı konamadığı durumlarda, tümörün gerçek yayılımını ortaya koymada, habis tümörlerde neoadjuvan kemoterapi cevabını değerlendirmede ve cerrahi öncesi planlamada yararlıdır. Konvansiyonel radyografiler özellikle pelvis, sakrum, vertebra gibi karmaşık

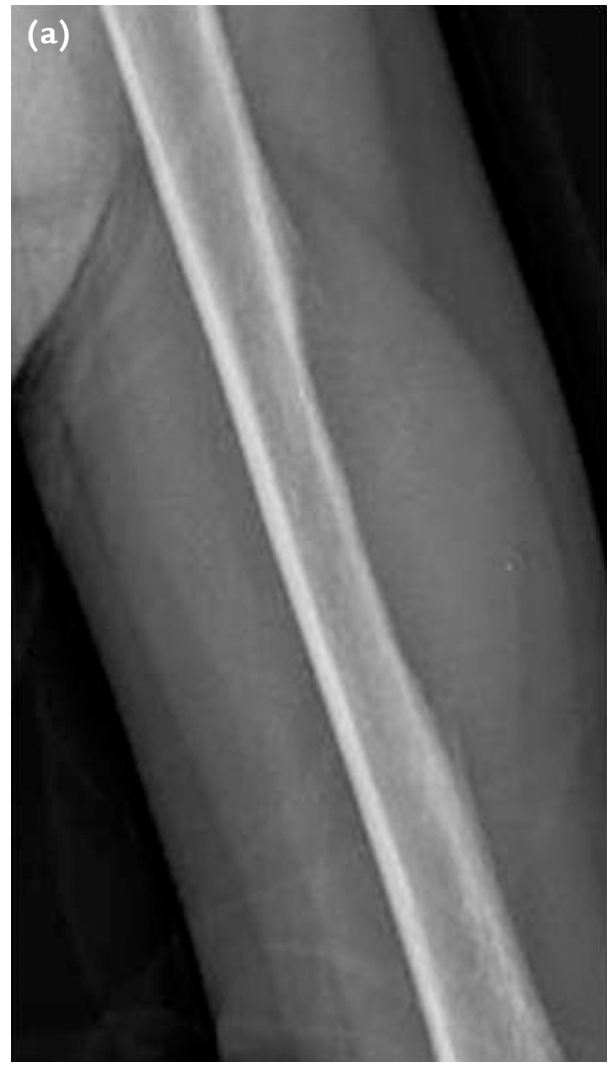

Şekil 4. a, b. Periost reaksiyonu habis kemik tümörlerine sıklıkla eşlik eder. Ewing sarkomlu iki farklı hastada, kesintili (a) ve 'soğan zarı' (lamellar) tarzında (b) periost reaksiyonları gözlenmekte. 

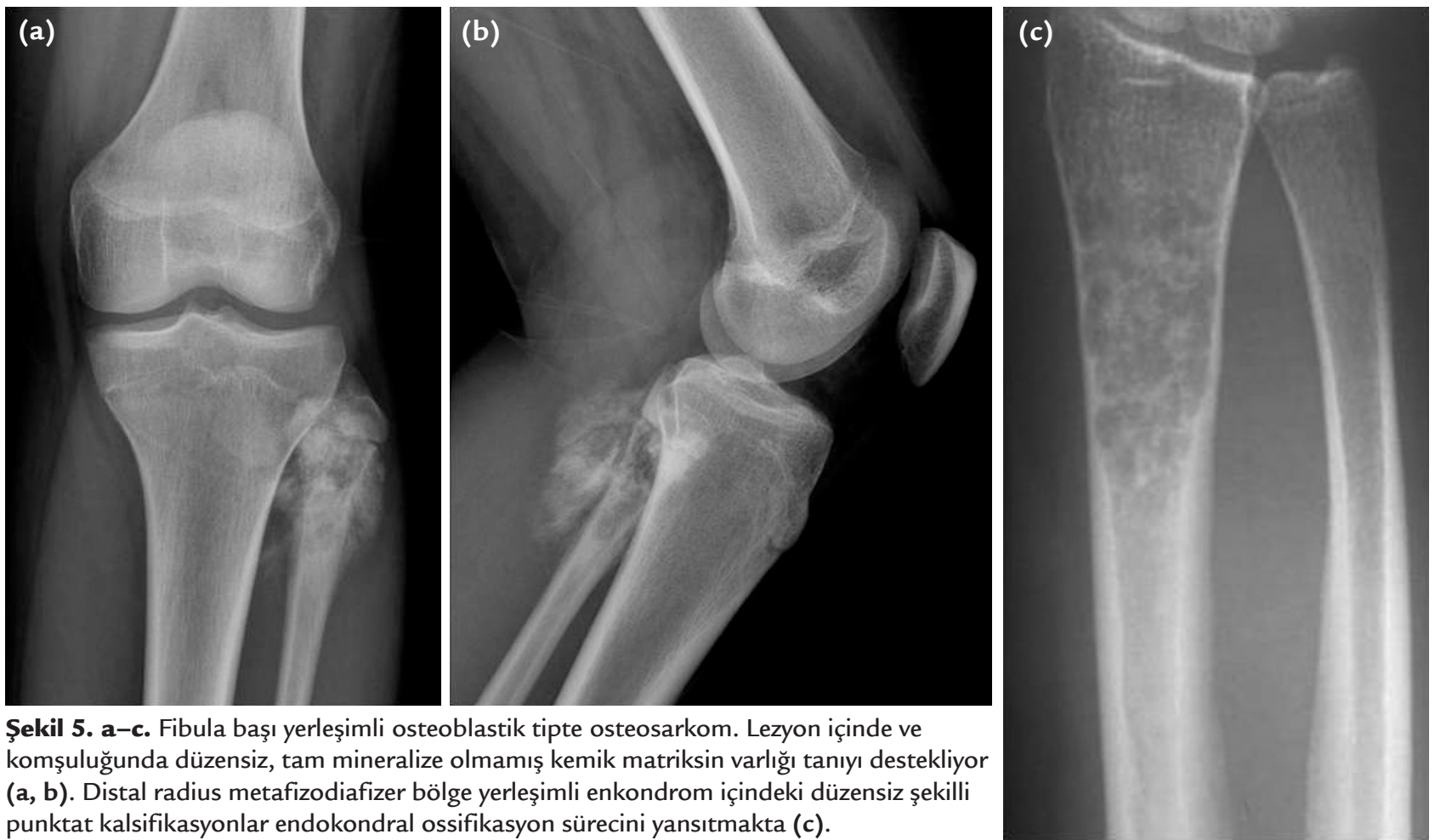

Şekil 5. a-c. Fibula başı yerleşimli osteoblastik tipte osteosarkom. Lezyon içinde ve komşuluğunda düzensiz, tam mineralize olmamış kemik matriksin varlığı tanıyı destekliyor (a, b). Distal radius metafizodiafizer bölge yerleşimli enkondrom içindeki düzensiz şekilli punktat kalsifikasyonlar endokondral ossifikasyon sürecini yansıtmakta (c).

anatomiye sahip lokalizasyonları iyi değerlendiremez; bu lokalizasyonlarda BT ve MR görüntüleme özellikle yardımcıdır. Radyoizotop kemik sintigrafisi, BT ve MR görüntüleme, konvansiyonel radyografilerin normal göründüğü hastalarda kemik lezyonlarını erken dönemde gösterebilir.

\section{Bilgisayarlı tomografi}

Bilgisayarlı tomografi kesitsel anatomiyi gösterebilmesi ve tümörün gerçek anatomik yayılımını ortaya koyabilmesi gibi özellikleri ile kas-iskelet sistemi görüntülemesinde, özellikle aksiyel iskelette, yararlıdır. Kortikal ve medüller kemik tutulumu, periosteal yeni kemik oluşumu, kemik tümörünün yumuşak doku komponenti ve yumuşak doku tümörleri BT ile ortaya konabilir. Fakat bu modalite kemik iliğini ve yumuşak dokuyu, yani tümörün intra- ve ekstra-osseöz yayılımını, MR görüntüleme kadar iyi gösteremez. BT'nin diğer bir dezavantajı ise geniş anatomik alanları etkili bir şekilde görüntüleyememesidir. BT korteksin içinde veya hemen komşuluğunda yer alan lezyonları göstermede çok yardımcıdır; ince-kesit (1-1,5 mm) BT osteoid osteomada nidusu en iyi tespit eden görüntülemedir (Şekil 6 a, b). ${ }^{[3,8]}$ BT, lezyon içi mineralizasyonun gösterilmesinde ve kortikal bütünlüğün değerlendirilmesinde de oldukça yararlıdır; intralezyonel kalsifikasyon odaklarını göstererek kıkırdak doku tümörlerine tanı konmasında ve kortikal devamlılığ, endosteal erozyonu değerlendirerek enkondrom, düşük-gradlı kondrosarkom ayırıcı tanısında yardımcı olur (Şekil 7 a-c). [8] Ayrıca, dev hücreli kemik tümörü gibi kortikal bütünlüğü sıklıkla bozan, metafizoepifizer bölgeden subkondral kemiğe, hatta eklem içine kadar uzanan lezyonların gerçek yayılımlarını ortaya koymada etkilidir. Tüm bunların yanısıra, kas-iskelet lezyonlarının perkütan biyopsileri BT yardımı ile gerçekleştirilir.

\section{Manyetik rezonans görüntüleme}

Manyetik rezonans görüntülemenin üç farklı planda (koronal, sagittal, aksiyel) görüntü üretebilme yeteneği birçok tümörün yayılımını belirlemede belirgin bir avantaj oluşturur. Koronal ve sagittal planlar uzun eksen görüntüleri oluşturarak bir lezyonun yerleşimini ve yayılımını (intra/ekstra-osseöz yayılım) belirler. Aksiyel plan ise tümörün kemik, yumuşak doku, sinirler ve damarlar ile ilişkisini en iyi şekilde ortaya koyar. Tüm bu özellikleri ile kemik ve yumuşak doku sarkomlarının evreleme, cerrahi öncesi kemoterapi yanıtını değerlendirme ve uzun-dönem izlemlerinde artık alışılagelmiş olan MR görüntüleme, selim kemik tümörlerinin tanı aşamasında da önemli bir yer edinmiştir. 

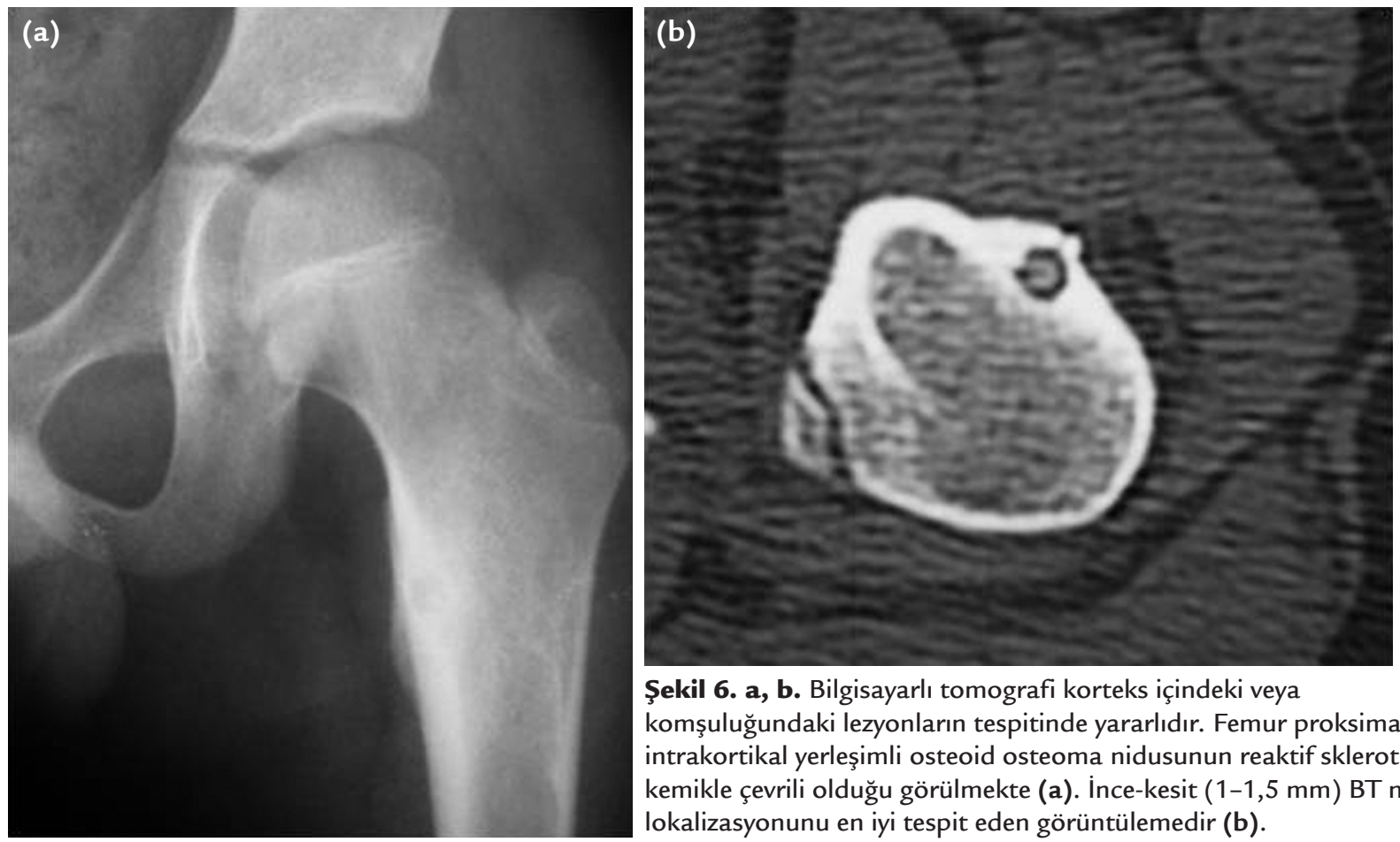

Şekil 6. a, b. Bilgisayarlı tomografi korteks içindeki veya komşuluğundaki lezyonların tespitinde yararlıdır. Femur proksimalinde intrakortikal yerleşimli osteoid osteoma nidusunun reaktif sklerotik kemikle çevrili olduğu görülmekte (a). İnce-kesit (1-1,5 mm) BT nidusun lokalizasyonunu en iyi tespit eden görüntülemedir (b).
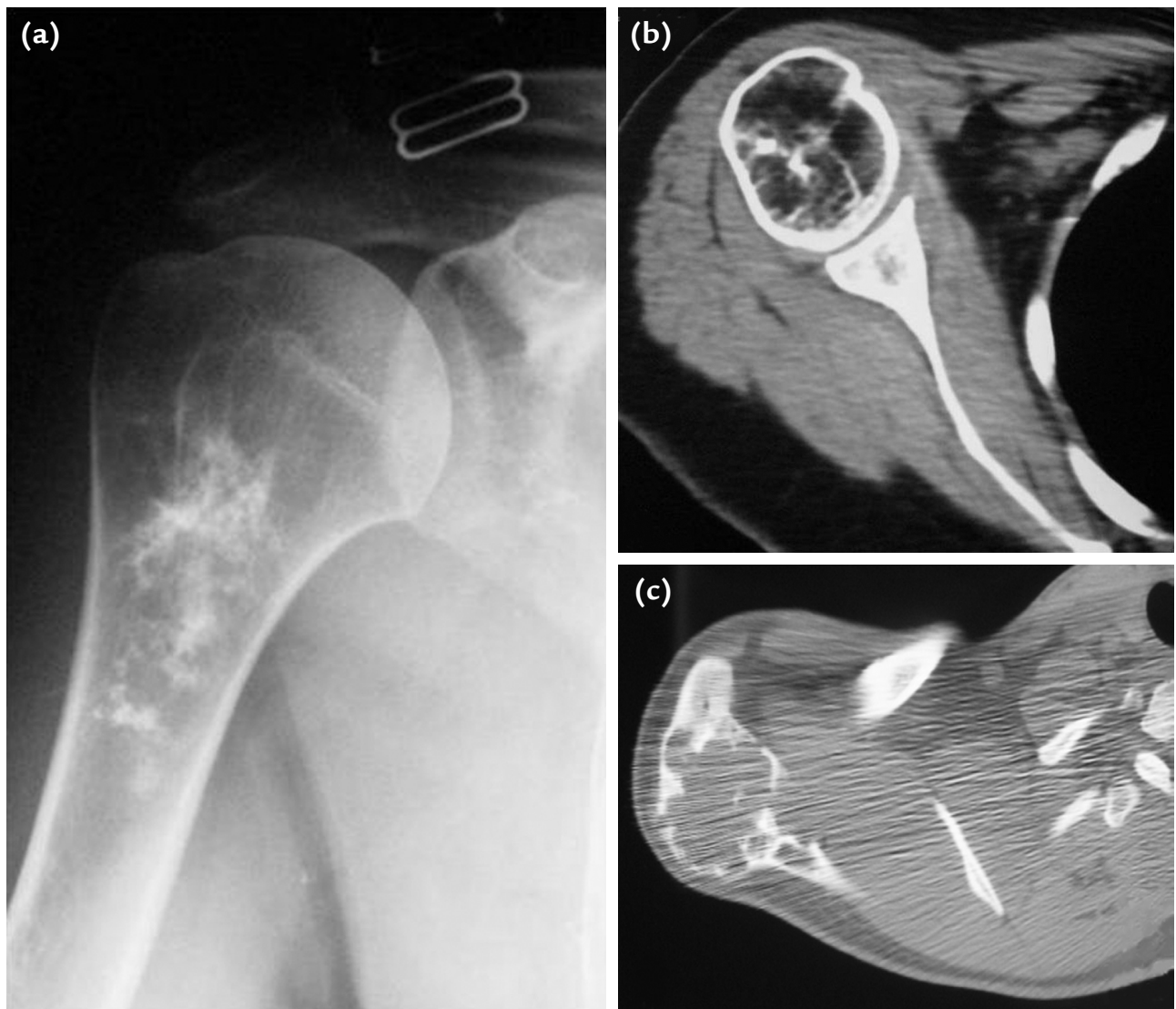

Şekil 7. a-c. Proksimal humerus yerleşimli bir enkondroma ait intralezyonel kalsifikasyonlar konvansiyonel radyografide (a) ve BT'de (b) izlenmekte. BT kesitinde kortikal devamlılığın bozulmadığı ve endosteal erozyon olmadığı görülüyor. Akromiyon yerleşimli bu düşük-gradlı kondrosarkomun BT görüntülemesinde ise kortikal bütünlüğün bozulduğu ve belirgin endosteal erozyon meydana geldiği izleniyor (c). 
Çocuklarda MR görüntülemede kistik bir kemik lezyonu içinde sıvı-sıvı seviyelerinin görülmesi anevrizmal kemik kistleri için neredeyse patognomoniktir (Şekil 8 a, b); bu bulgu çocuklarda sık görülen basit ve anevrizmal kemik kistlerinin ayırımında çok yardımcıdır. ${ }^{[1,4]}$ Bunun yanı sıra, patolojik kırık geçirmiş bir basit kemik kistinde intra-kistik hemorajiye bağlı sıvı-sıvı seviyelerinin görülebileceği ve yanlışııkla anevrizmal kemik kisti ile karıştırılabileceği de akılda tutulmalıdır. MR görüntüleme bazı durumlarda abartılı görünüm vererek selim bir kemik tümörünün (ör., osteoid osteoma, eozinofilik granülom) habis bir lezyon olarak değerlendirilmesine yol açabilir (Şekil 9 a, b). Eklem tutulumunu ve epifizyel yayılımı göstermesi MR görüntülemenin BT'ye diğer üstünlükleridir ve selim kemik tümörlerinin tedavi planlamasında oldukça yararlıdır. Osteokondromların (daha sık multipl herediter ekzositözde) habis transformasyon göstermesi durumunda, klinik bulgularla beraber, MR görüntülemede kıkırdak şapka kalınlığının ölçülmesi tanıya
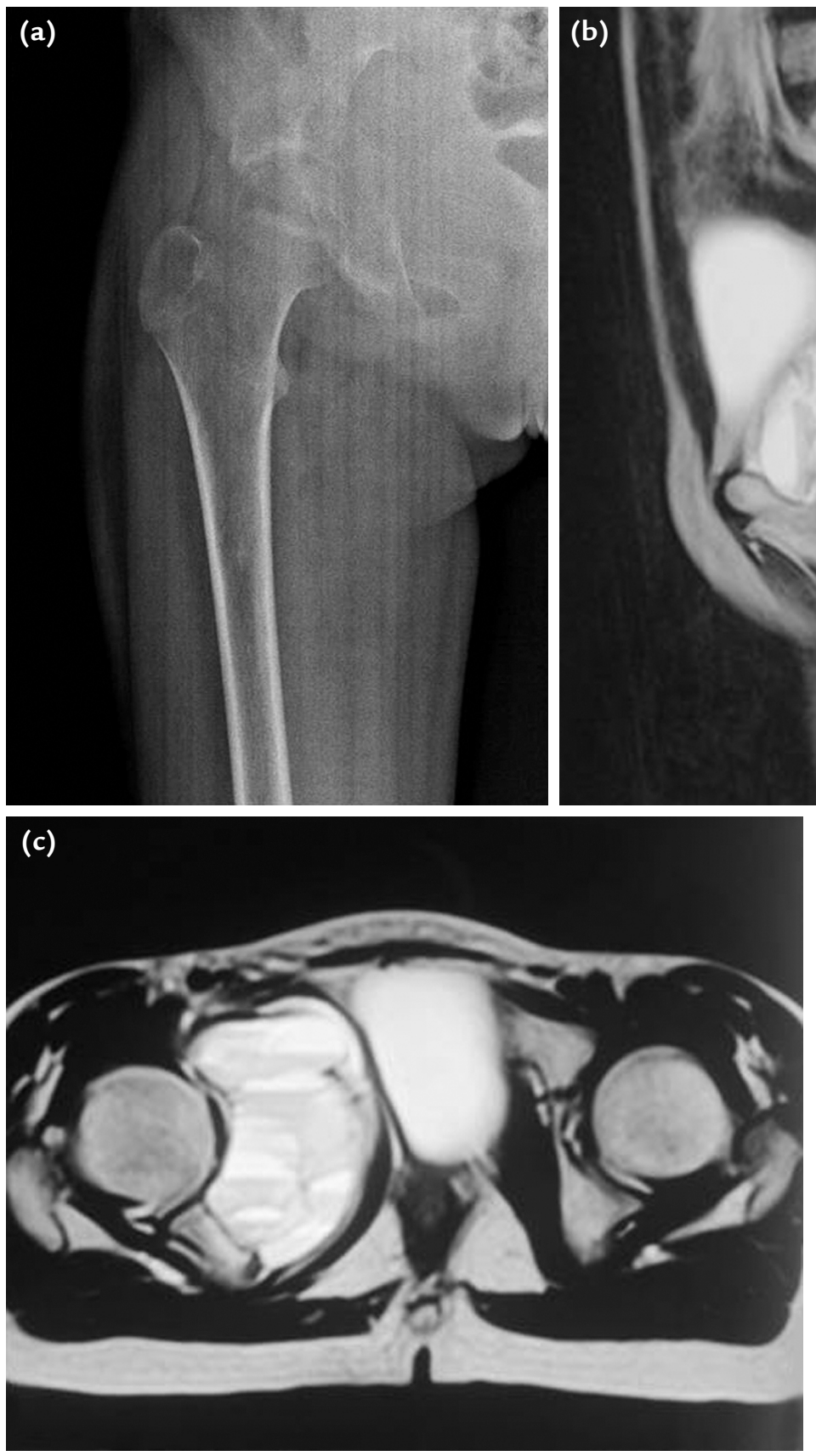

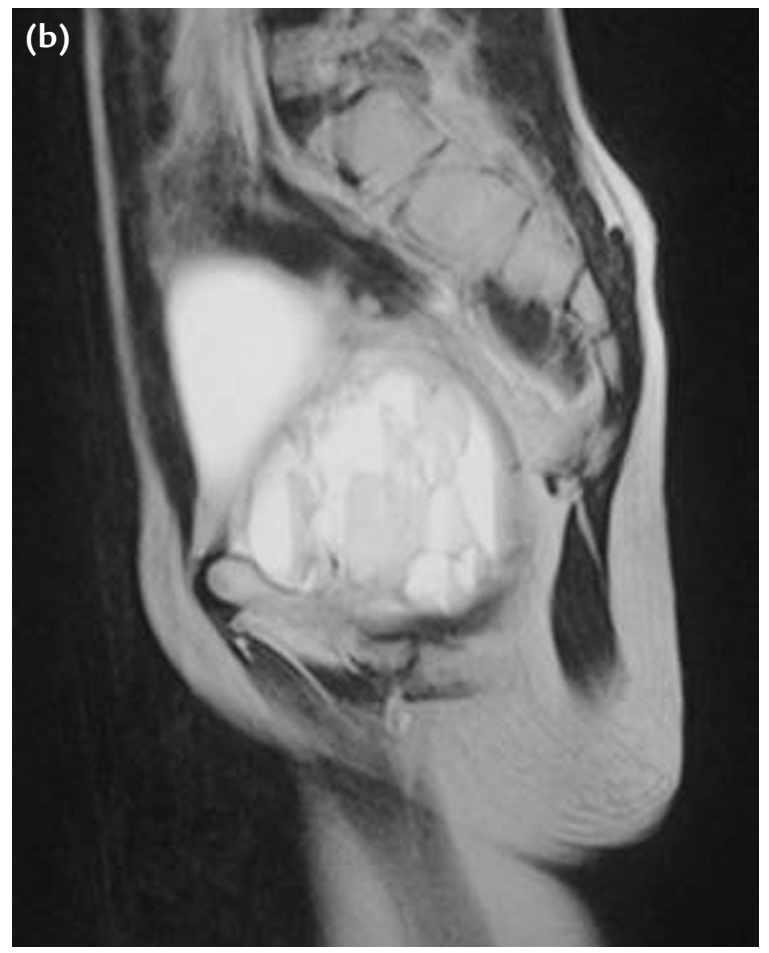

Şekil 8. a-c. On üç yaşında bir kız hastada asetabulum yerleşimli anevrizmal kemik kistinin, radyografik (a) ve sagittal ve aksiyel MR görüntüleri $(b, c)$. Çocuklarda MR görüntülemede intralezyonel sıvı-sıvı seviyelerinin izlenmesi anevrizmal kemik kisti için patognomonik kabul edilir. 


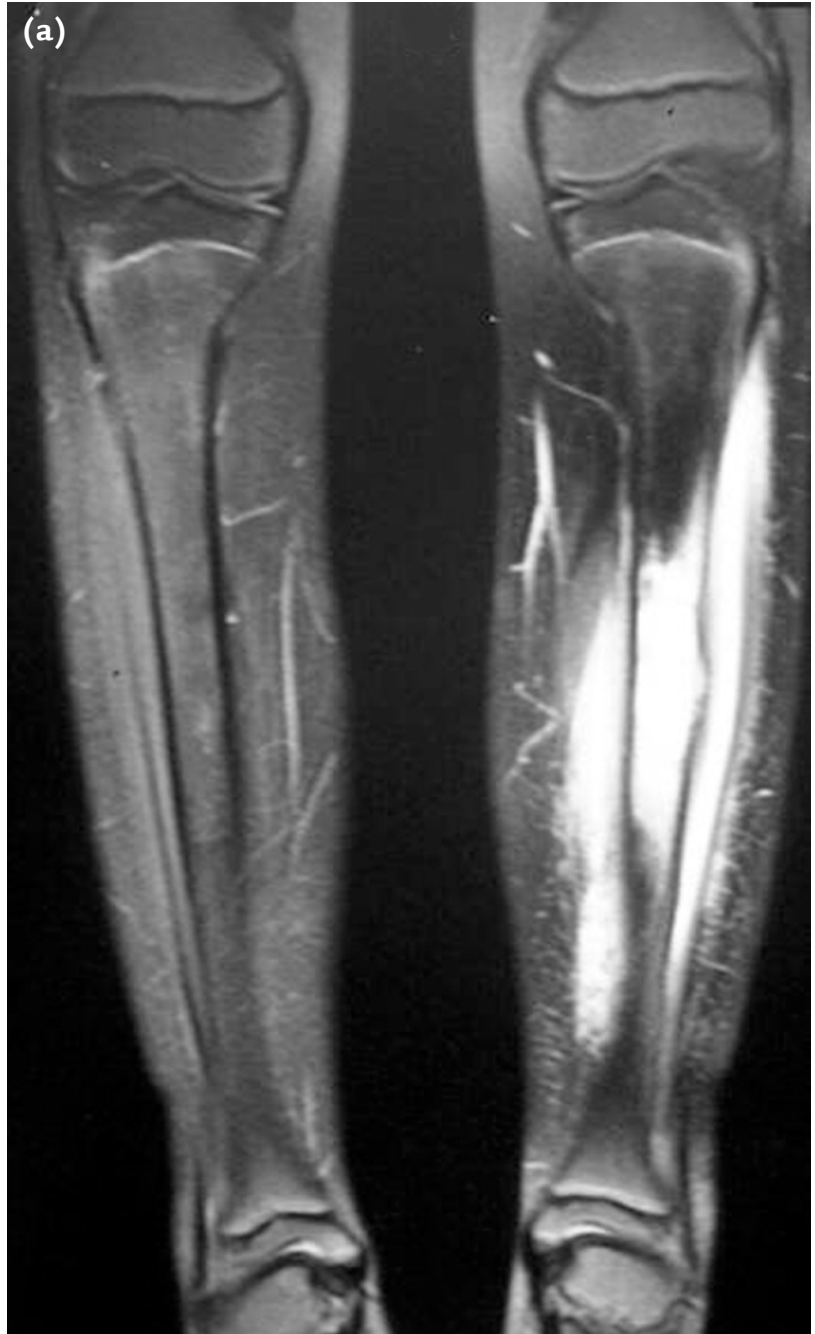

yardımcı olur; kalınlığın 1,5-2 santimetreden fazla olması habis dönüşüm lehine değerlendirilir. ${ }^{[8]}$

\section{Tüm vücut kemik sintigrafisi}

Radyonüklid kemik sintigrafisi mineral dönüşümünün bir göstergesidir. Kemik yapısında değişikliklerin veya tamir süreçlerinin olduğu bölgelerde özgün radyofarmasötik ajanların depolanması artar ve bu şekilde kemik sintigrafisi iskeletteki tümörleri veya tümör-benzeri lezyonları lokalize edebilir. Tüm vücut kemik sintigrafisi iskeletin tamamını taramada en pratik yöntemdir; habis tümörlerde radyolojik evrelemede (metastaz taramasında) kullanılan bu özellik, selim kemik tümörleri açısından düşünüldüğünde iskelette multipl tutulumla giden poliostotik lezyonların (ör., poliostotik fibröz displazi, enkondromatozis, multipl herediter egzositöz) yayılımını belirlemede çok yararlıdır. ${ }^{[1,4]}$ Özellikle artmış kemik üretimi (osteoblastik

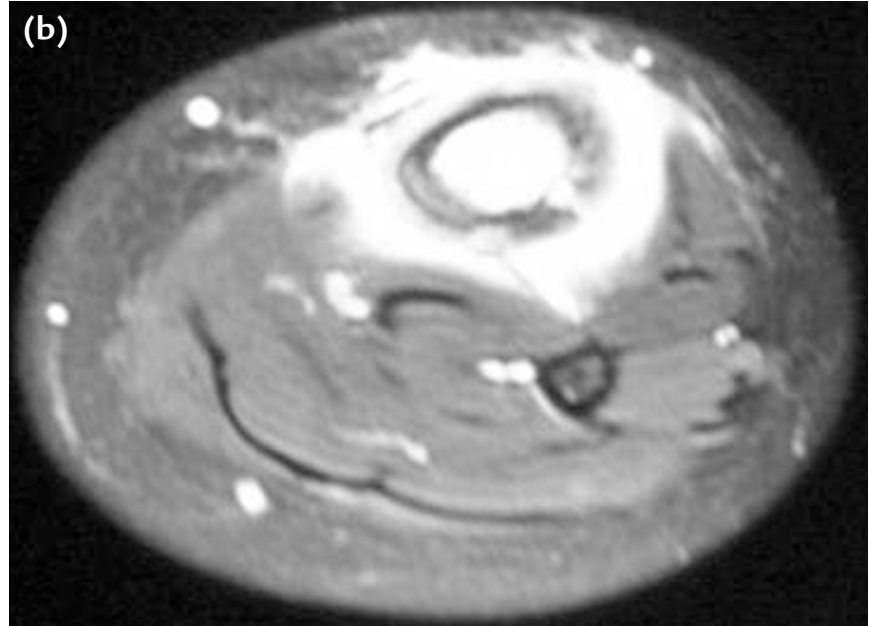

Şekil 9. a, b. Tibia diafizinde yerleşmiş bir eozinofilik granülomun, koronal (a) ve aksiyel (b) MR görüntüleri. Görüntüler yaygın intraosseöz yayılımın yanısıra, kemik çevresinde belirgin bir ödemin varlığını da ortaya koymakta. MR görüntülemedeki bu abartılı tablo, lezyonun yanlışlıkla habis bir tümör olarak değerlendirilmesine yol açabilir. aktivite) ile giden aktif ve agresif selim lezyonlar ile habis neoplaziler teknetyum-99'un lokal konsantrasyonunu arttırır ve sintigrafide 'sıcak nokta' oluşturur. Bazı durumlarda (ör., eozinofilik granülom, miyelom) kemik sintigrafisi yalancı negatiflik verebilir. Kemik sintigrafisindeki anormal tutulumun derecesi ile lezyonun agresifliği ilişkili olmakla beraber bunun histolojik grad ile uyum göstermediği unutulmamalıdır. ${ }^{[8]}$

\section{BIYOPSI/HISTOPATOLOJi}

Biyopsi, hastanın değerlendirilmesindeki son basamak olmalı, radyolojik evrelemeyi takiben yapılmalıdır. Biyopsinin amacı cerrah tarafindan şüphelenilen tanının doğrulanması veya sınırı sayıda ayırıcı tanı içinden hangisinin doğru olduğunun belirlenmesidir. İyi planlanmış bir biyopsi doğru tanıya ulaşılmasını sağlar ve tedaviyi kolaylaştırır. Diğer taraftan, kötü yapılmış bir 
biyopsi ile bunun başarılması güçtür. Biyopsinin, tümörün definitif tedavisinin yapılacağı merkezde gerçekleştirilmesi önemlidir.

Bir kas-iskelet sistemi tümörü için en iyi biyopsi metodu, ayırıcı tanıya, tümörün yerleşimine ve patoloğun ne miktarda bir örnekle tanı koyabileceğine bağlıdır. ${ }^{[9]}$ Bu tümörlerin tanısında kapalı (ince iğne aspirasyon, tru-cut) veya açık (insizyonel, eksizyonel) biyopsi yöntemleri uygulanabilir. Lezyonun tanısı konusunda herhangi bir şüphe varsa, tanı definitif tedavi öncesinde histopatolojik inceleme ile mutlaka kesinleştirilmelidir. Tru-cut biyopsi veya insizyonel biyopsi en sık kullanılan yöntemlerdir. Kapalı (tru-cut) veya açık (insizyonel) kemik biyopsilerinde, biyopsi yolu kontamine kabul edilir ve daha sonra yapılacak definitif cerrahi sırasında çıkarılabilecek şekilde planlanmalıdır. Ekstremitelerde, tanı için yeterli doku örneğinin alınmasına olanak veren en kısa insizyonlar longitudinal olarak uygulanmalıdır. Transvers insizyonlar, biyopsi sırasında çok daha geniş bir alanın kontamine bırakılmasına neden olur. Bu durum definitif cerrahide rezeke edilecek doku miktarını ve morbiditeyi arttırır.

İnsizyonel biyopsi kesisinin sadece bir kompartmandan geçecek şekilde yapılması, işlem sırasında yaratılan kontaminasyonun daha az olmasını sağlayarak definitif cerrahi sırasında rezeke edilecek doku miktarını azaltır. İnsizyonel biyopside ciltten tümöre en doğrudan yol izlenir; intermusküler plan yerine kas içinden (intramusküler) ilerlenmesi kuraldır. Ayrıca, önemli nörovasküler yapılardan uzak durulmalıdır. Doku örneğinin alınmasını takiben kapamaya geçmeden çok iyi bir hemostaz yapılması, tümör hücreleri ile kontamine hematom miktarını azaltır. Kemikte açılan oval deliğin kemik mumu veya kemik çimentosu (PMMA) ile kapatılması da kontaminasyonun azaltılmasında önemlidir. Eğer dren yerleştirilecekse, insizyona yakın ve aynı hat üzerinde olmalıdır. Kemik biyopsilerinde turnike uygulaması yapılabilir ama ekstremitedeki kanın bandajla sarılarak değil, elevasyonda bekletilerek boşaltılması önerilir.

\section{KAYNAKLAR}

1. Erol B, Dormans JP. Musculoskeletal tumors in children. In: Dormans JP, editor. Core knowledge in orthopaedics. Philadelphia: Mosby-Elsevier; 2005. p.291-336.

2. Heck Jr R. General principles of tumors. In: Canale ST, Beaty $\mathrm{JH}$, editors. Campbell's Operative Orthopaedics. 11th ed. Philadelphia: Mosby Elsevier; 2008. p.775-854.

3. Erol B, Dormans JP, States L, Pawel B. Tumors. In: Cramer KE, Scherl SA, editors. Orthopaedic surgery essentials. Pediatrics: orthopaedic essentials. Philadelphia: Lippincott Williams \& Wilkins; 2004. p.251-70.

4. Erol B, ErT, Rodop O, Olgaç V. Çocuklarda kas-iskelet sistemi tümörleri. In: Çullu E, editor. Çocuk ortopedisi. İstanbul: Bayçınar Tıbbi Yayıncılık; 2012. p.243.

5. Enneking WF, editor. Musculoskeletal tumor surgery. New York, NY: Churchill Livingstone; 1983.

6. Madewell JE, Ragsdale BD, Sweet DE. Radiologic and pathologic analysis of solitary bone lesions: Part I: Internal margins. Radiol Clin North Am 1981;19(4):715-48.

7. Ragsdale BD, Madewell JE, Sweet DE. Radiologic and pathologic analysis of solitary bone lesions: Part II: periosteal reactions. Radiol Clin North Am 1981;19(4):749-83.

8. Greenspan A, Jundt G, Remagen W. Differential Diagnosis in Orthopaedic Oncology. 2nd ed. Philadelphia: Lippincott Williams \& Wilkins; 2007.

9. Simon MA, Springfield D, editors. Surgery for Bone and SoftTissue Tumors. Philadelphia, PA: Lippincott-Raven; 1998. 